\title{
Regulation of calmodulin-stimulated cyclic nucleotide phosphodiesterase (PDE1): Review
}

\author{
RAJENDRA K. SHARMA, SHANKAR B. DAS, ASHAKUMARY LAKSHMIKUTTYAMMA, \\ PONNIAH SELVAKUMAR and ANURAAG SHRIVASTAV
}

\begin{abstract}
Department of Pathology and Laboratory Medicine, College of Medicine, University of Saskatchewan, Cancer Research Division, Saskatchewan Cancer Agency, 20 Campus Drive, Saskatoon SK S7N 4H4, Canada
\end{abstract}

Received January 16, 2006; Accepted March 13, 2006

\begin{abstract}
The response of living cells to change in cell environment depends on the action of second messenger molecules. The two second messenger molecules cAMP and $\mathrm{Ca}^{2+}$ regulate a large number of eukaryotic cellular events. Calmodulin-stimulated cyclic nucleotide phosphodiesterase (PDE1) is one of the key enzymes involved in the complex interaction between cAMP and $\mathrm{Ca}^{2+}$ second messenger systems. Some PDE1 isozymes have similar kinetic and immunological properties but are differentially regulated by $\mathrm{Ca}^{2+}$ and calmodulin. Accumulating evidence suggests that the activity of PDE1 is selectively regulated by cross-talk between $\mathrm{Ca}^{2+}$ and cAMP signalling pathways. These isozymes are also further distinguished by various pharmacological agents. We have demonstrated a potentially novel regulation of PDE1 by calpain. This study suggests that limited proteolysis by calpain could be an alternative mechanism for the activation of PDE1. We have also shown PDE1 activity, expression and effect of calpain in the rat model in vitro of cardiac ischemiareperfusion.
\end{abstract}

\section{Contents}

1. Introducton

2. Kinetic properties of various PDE1 isozymes

3. Differential regulation of PDE1 by $\mathrm{CaM}$ and $\mathrm{Ca}^{2+}$

4. Coupling between $\mathrm{Ca}^{2+}$ and cAMP second messengers in the regulation of PDE1

5. Role of autophosphorylation of PDE1B1 by CaMdependent protein kinase II

Correspondence to: Dr Rajendra K. Sharma, Department of Pathology and Laboratory Medicine, College of Medicine, University of Saskatchewan, Cancer Research Division, 20 Campus Drive, Saskatoon SK S7N 4H4, Canada

E-mail: rsharma@scf.sk.ca

Key words: calmodulin-stimulated cyclic nucleotide phosphodiesterase, regulation, calpains, ischemia, reperfusion
6. Differential inhibition of PDE1 isozymes and its therapeutic applications

7. Role of proteolysis in regulating PDE1A2

8. Role of PDE1A1 in ischemic-reperfused heart

9. Conclusion

\section{Introduction}

A variety of cellular activities are regulated through mechanisms controlling the level of cyclic nucleotides. These mechanisms include synthesis, degradation, efflux and sequestration of cyclic adenosine $3^{\prime}: 5^{\prime}$-monophosphate (cAMP) and cyclic guanosine $3^{\prime}: 5^{\prime}$ - monophosphate (cGMP) within the cell. Hydrolysis of the cyclic nucleotides by cyclic nucleotide phosphodiesterases (PDEs) is a unique mechanism for the degradation of cyclic nucleotides. The PDEs isolated from various tissues differ in their substrate specificities, in their substrate affinities and in their sensitivity to a variety of natural and artificial effectors. The variability has been observed even among the enzymes isolated from a single tissue. The presence of multiple forms of PDE within a single tissue or cell type has been a consistent finding.

Initially, the multiple forms of PDE were classified into three categories: cAMP PDE, cGMP PDE and PDEs based on their marked differences in relative affinities towards cyclic nucleotides $(1,2)$. One of these forms of enzymes is activated by $\mathrm{Ca}^{2+}$ /calmodulin $(\mathrm{CaM})$ and has a lower apparent $\mathrm{K}_{m}$ value for cGMP than for cAMP and a higher $\mathrm{V}_{\max }$ for cAMP than for cGMP. CaM-stimulated PDE (PDE1) has been extensively studied from mammalian tissues (3-9). In most cases, the activation of PDE1 is initiated by binding of $\mathrm{Ca}^{2+}$ to free $\mathrm{CaM}$ to convert the protein from an inactive state to an active conformation $\left(\mathrm{Ca}^{2+}-\mathrm{CaM}^{*}\right)$. This activated $\mathrm{CaM}^{*}$ is then associated with the PDE1 to result in the active PDE1 $\left(\mathrm{Ca}^{2+}-\right.$ $\left.\mathrm{CaM}^{*}-\mathrm{PDE} 1^{*}\right)$.

Several groups of investigators including ourselves have purified a number of PDE1 from bovine tissues to apparent homogeneity which have a different molecular weights and different subunit structure as well as distinct catalytic and regulatory properties (3-9). It was initially thought that a single form of PDE1 existed in a variety of tissues (10). However, Sharma et al (11) provided the first direct evidence for the existence of different isozymic forms of bovine tissue 
Table I. Kinetic properties of PDE1 isozymes from bovine tissues.

\begin{tabular}{lccccc}
\hline & \multicolumn{2}{c}{$\mathrm{K}_{m}(\mu \mathrm{M})$} & & \multicolumn{2}{c}{$\mathrm{V}_{\max }(\mu \mathrm{mol} / \mathrm{min} / \mathrm{mg})$} \\
\cline { 2 - 3 } \cline { 6 - 7 } Isozyme & $\mathrm{c}$ AMP & $\mathrm{cGMP}$ & & $\mathrm{cAMP}$ & $\mathrm{cGMP}$ \\
\hline PDE1B1 & 12.0 & 1.2 & & 10.0 & 30.0 \\
PDE1A2 & 35.0 & 2.7 & & 166.0 & 93.0 \\
PDE1A1 & 40.0 & 3.2 & & 133.0 & 44.0 \\
Lung PDE1 & 42.0 & 2.8 & & 82.0 & 47.0 \\
\hline
\end{tabular}

For details, see ref. 15.

PDE1, and initially these isozymes were designated according to tissue origin and subunit molecular mass. Since the list of PDE1 isozymes is increasing, a new nomenclature of these isozymes has been suggested by using molecular biology studies, e.g. PDE1B1 (brain 63 kDa PDE1), PDE1A2 (brain $60 \mathrm{kDa}$ PDE1), PDE1A1 (59 kDa heart PDE1) and PDE1C (70 kDa PDE1) (12). At least eleven gene families of PDEs are known to exist (13).

These PDE1 isozymes show subtle differences in kinetic, regulatory properties by $\mathrm{CaM}, \mathrm{Ca}^{2+}$, phosphorylation/ dephosphorylation and differential inhibition by various pharmacological agents. Furthermore, a potentially novel form of PDE1 regulation by proteolysis and their role in ischemia and reperfusion injury has been observed. The purpose of this review is to summarize some of the most significant advances which have been carried out in our laboratory.

\section{Kinetic properties of various PDE1 isozymes}

In order to elucidate the physiological significance of the PDE1 isozymes, the purified isozymes were characterized in terms of catalytic properties. Table I shows that PDE1B1, PDE1A2, PDE1A1 and lung PDE1 isozymes have a higher affinity towards cGMP than cAMP. In addition, PDE1A1, PDE1A2 and lung PDE1 isozymes have very similar $\mathrm{K}_{m}$ value whereas the PDE1B1 has a 2-3 fold higher affinity for both substrates (cAMP and cGMP) and a higher $\mathrm{V}_{\max }$ for cGMP than for cAMP. These results indicate that the PDE1B1 isozyme is kinetically distinct from the other three PDE1 isozymes.

\section{Differential regulation of PDE1 by $\mathrm{CaM}$ and $\mathrm{Ca}^{2+}$}

Although PDE1A1, PDE1A2, lung PDE1 and eye PDE1 isozymes are almost identical both kinetically and immunologically, they are differentially regulated by $\mathrm{CaM}$ and $\mathrm{Ca}^{2+}$ (14-18). The interaction of $\mathrm{Ca}^{2+} / \mathrm{CaM}$ and PDE1 in a CaM-stimulated reaction is the inter-dependence of $\mathrm{Ca}^{2+}$ binding to $\mathrm{CaM}$ and the association of $\mathrm{CaM}$ and the enzyme. Various laboratories reported that PDE1A1 had a markedly higher CaM affinity than PDE1B1 and PDE1A2 isozymes (14-18). However, PDE1B1 and PDE1A2 had similar affinity for CaM, but $\sim 10-20$-fold lower than that of the PDE1A1 isozymes $(15,16)$. The difference in CaM affinities of isozymes from different tissues has been suggested to represent a mechanism whereby the isozymes accommodate intracellular CaM concentrations of the respective tissues. However, the lung PDE1 isozyme, which contains $\mathrm{CaM}$ as a subunit, may be considered the extreme case of a higher affinity CaM binding (19). We have observed that at an identical CaM concentration, PDE1A1 and eye PDE1 isozymes are stimulated at much lower $\mathrm{Ca}^{2+}$ concentration than is the PDE1B1 and PDE1A2 (Table II). These results may suggest that differential $\mathrm{Ca}^{2+}$ affinity of the tissue specific isozymes may be a mechanism by which the CaM-regulatory reactions are adapted in the respective tissues.

\section{Coupling between $\mathrm{Ca}^{2+}$ and cAMP second messengers in the regulation of PDE1}

The interaction of $\mathrm{Ca}^{2+}$ and cAMP second messenger's cascades has been reviewed in detail (3). These two second messengers can interact at multiple sites on at least two levels. On the metabolic level, both cAMP metabolism and $\mathrm{Ca}^{2+}$ transport are regulated by both messengers. On the functional level, cellular processes regulated by one messenger can often be modulated by the other. The high degree of complexity in this interactive system could provide the cell with the flexibility required for producing a wide range of specific response reactions.

The activity of PDE1 isozymes can be regulated by several different mechanisms involving $\mathrm{Ca}^{2+}$ and cAMP; 1) phosphorylated and non-phosphorylated PDE1 isozymes require $\mathrm{Ca}^{2+}$ and $\mathrm{CaM}$ for full activity; 2) cAMP or $\mathrm{Ca}^{2+} / \mathrm{CaM}$ can stimulate PDE1 isozymes phosphorylation; 3 ) in case of the PDE1A2, PDE1A1 and eye PDE1 $\mathrm{Ca}^{2+} / \mathrm{CaM}$ can block phosphorylation, whereas $\mathrm{Ca}^{2+} / \mathrm{CaM}$ stimulate phosphorylation of PDE1B1 and; 4) $\mathrm{Ca}^{2+} / \mathrm{CaM}$ can reverse phosphorylation of PDE1 isozymes by CaM-dependent protein phosphatase (calcineurin). The multiple regulatory activities of each of the isozymes have to interact under certain defined conditions and their regulatory conditions are summarized in Table III. While PDE1A1, PDE1A2 and eye PDE isozymes are substrates of the cAMP-dependent protein kinase (20-22), the PDE1B1 is phosphorylated by $\mathrm{CaM}$-dependent protein kinase II in a $\mathrm{Ca}^{2+} / \mathrm{CaM}$-dependent manner (23). The phosphorylation of PDE1 results in a decrease in the affinity of the isozymes for $\mathrm{CaM}$ and an accompanying increase in the $\mathrm{Ca}^{2+}$ concentrations required for the isozymes activation by CaM (20-23).

For each of the PDE1 isozymes, a working hypothesis has been postulated to indicate how the multiple regulatory reactions may be organized in the cells to control cAMP concentrations $(3-5,8,9)$. Because these isozymes show low cAMP affinities and low basal PDE1 activities, a major assumption of this working hypothesis is that the isozymes function mainly during cell activations when both cAMP and $\mathrm{Ca}^{2+}$ concentrations are elevated. For the regulation of the PDE1A2, PDE1A1 and eye PDE1 isozymes, an increase in intracellular cAMP concentration at the onset of cell stimulation results in the activation of cAMP-dependent protein kinase; the phosphorylation of these isozymes may result in concomitant isozyme inhibition. This will ensure an unimpeded further increase in cAMP concentration. As cellular $\mathrm{Ca}^{2+}$ concentration is increased, the CaM-dependent 
Table II. $\mathrm{Ca}^{2+}$ activation of PDE1 isozymes at various concentrations of CaM.

\begin{tabular}{lccccc}
\hline & \multicolumn{5}{c}{$\left[\mathrm{Ca}^{2+}\right](\mu \mathrm{M})$ Required for half-maximal activation } \\
\cline { 2 - 5 } CaM $(\mu \mathrm{M})$ & $\begin{array}{c}\text { PDE1A1 } \\
\text { isoenzyme }\end{array}$ & $\begin{array}{c}\text { PDE1A2 } \\
\text { isoenzyme }\end{array}$ & $\begin{array}{c}\text { PDE1B1 } \\
\text { isoenzyme }\end{array}$ & $\begin{array}{c}\text { Lung PDE1 } \\
\text { isoenzyme }\end{array}$ & $\begin{array}{c}\text { Eye PDE1 } \\
\text { isoenzyme }\end{array}$ \\
\hline 0.1 & 0.71 & ND & ND & ND & 0.73 \\
0.5 & 0.36 & ND & ND & ND & 0.35 \\
1.00 & 0.08 & 0.90 & 0.70 & 0.15 & ND \\
10.0 & 0.01 & 0.35 & 0.30 & 0.15 & ND \\
\hline
\end{tabular}

ND, not determined. For details, see refs. 14,15.

Table III. Regulation of PDE1 isozymes by $\mathrm{Ca}^{2+}$ and cAMP.

\begin{tabular}{|c|c|}
\hline Isozyme & Regulation \\
\hline Brain PDE1A2 & 1. Activation by $\mathrm{Ca}^{2+}$ and $\mathrm{CaM}$. \\
\hline Heart PDE1A1 & 2. Phosyphorylation by cAMP-dependent protein kinase to result in an increase \\
\hline Eye PDE1 isozyme & in the $\mathrm{Ca}^{2+}$ concentration required for phosphodiesterase activation. \\
\hline & 3. Blockage of phosphodiesterase phosphorylation by $\mathrm{Ca}^{2+}$ and $\mathrm{CaM}$. \\
\hline & 4. Reversal of the phosphorylation by CaM-dependent phosphatase. \\
\hline \multirow[t]{3}{*}{ Brain PDE1B1 } & 1. Activation by $\mathrm{Ca}^{2+}$ and $\mathrm{CaM}$. \\
\hline & $\begin{array}{l}\text { 2. Phosyphorylation by } \mathrm{CaM} \text {-dependent protein kinase II to result in an increase } \\
\text { in the } \mathrm{Ca}^{2+} \text { concentration required for phosphodiesterase activation. }\end{array}$ \\
\hline & 3. Reversal of the phosphorylation by CaM-dependent phosphatase. \\
\hline
\end{tabular}

For details, see refs. 19-24.

protein phosphatase is activated to reverse the phosphorylation of PDE1A2, PDE1A1 and eye PDE1, and the dephosphorylated isozymes are then activated by $\mathrm{Ca}^{2+}$ and $\mathrm{CaM}$. Because the association of $\mathrm{CaM}$ to these isozymes prevents the phosphorylation of the isozymes by the protein kinase (Table III), the isozymes will remain in its dephosphorylated state even if cAMP concentration remains high. The concerted actions of $\mathrm{Ca}^{2+}$ and $\mathrm{CaM}$ on the phosphatase reaction, the phosphorylation reaction, and PDE1 isozymes activity lead to a decline in cAMP concentration in the cells.

The multiple regulatory reactions for PDE1B1 all involve $\mathrm{Ca}^{2+}$ and CaM (Table III), and they can affect the PDE1B1 activity in opposite directions. The CaM-stimulation of the isozyme is partly opposed by the CaM-dependent isozyme phosphorylation, which, in turn, is counteracted by the CaM-stimulated phosphatase reaction. To reconcile such opposing effects by $\mathrm{Ca}^{2+} / \mathrm{CaM}$, it is postulated that the distinct $\mathrm{CaM}$-dependent regulatory reactions are temporally separated during the cell stimulation; that is, the protein kinases, which act in concert with adenylate cyclase to increase cAMP concentrations, are activated by CaM prior to the activation of the phosphatase and the PDE1B1. Activation of PDE results in a decline in intracellular cAMP concentrations.

\section{Role of autophosphorylation of PDE1B1 by CaM- dependent protein kinase II}

Like other protein kinase II isozymes, bovine brain CaMstimulated protein kinase II converts from a CaM-dependent to a CaM-independent active protein kinase upon autophosphorylation. The desensitization of the autophosphorylation reaction to $\mathrm{Ca}^{2+}$ and $\mathrm{CaM}$ occurs within a few seconds. Both autophosphorylation and the phosphorylation of PDE1B1 by the CaM-dependent protein kinase II are independent of $\mathrm{Ca}^{2+}$ within $15 \mathrm{sec}$ (24). Thus, one possible mechanism wherein a temporal separation of PDE1B1 phosphorylation from CaM-stimulations of PDE1B1 dephosphorylation and PDE1B1 activity is achieved may be through the CaM-dependent protein kinase II autophosphorylation reaction. A more detailed description of bovine brain CaM-stimulated protein kinase II and discussion of the role of its autophosphorylation in the regulation of PDE1B1 have been reviewed $(3-5,8,9)$.

\section{Differential inhibition of PDE1 isozymes and its therapeutic applications}

PDEs are involved in maintaining (attenuating) the dynamic changes in the levels of cAMP and cGMP. In most cells and 


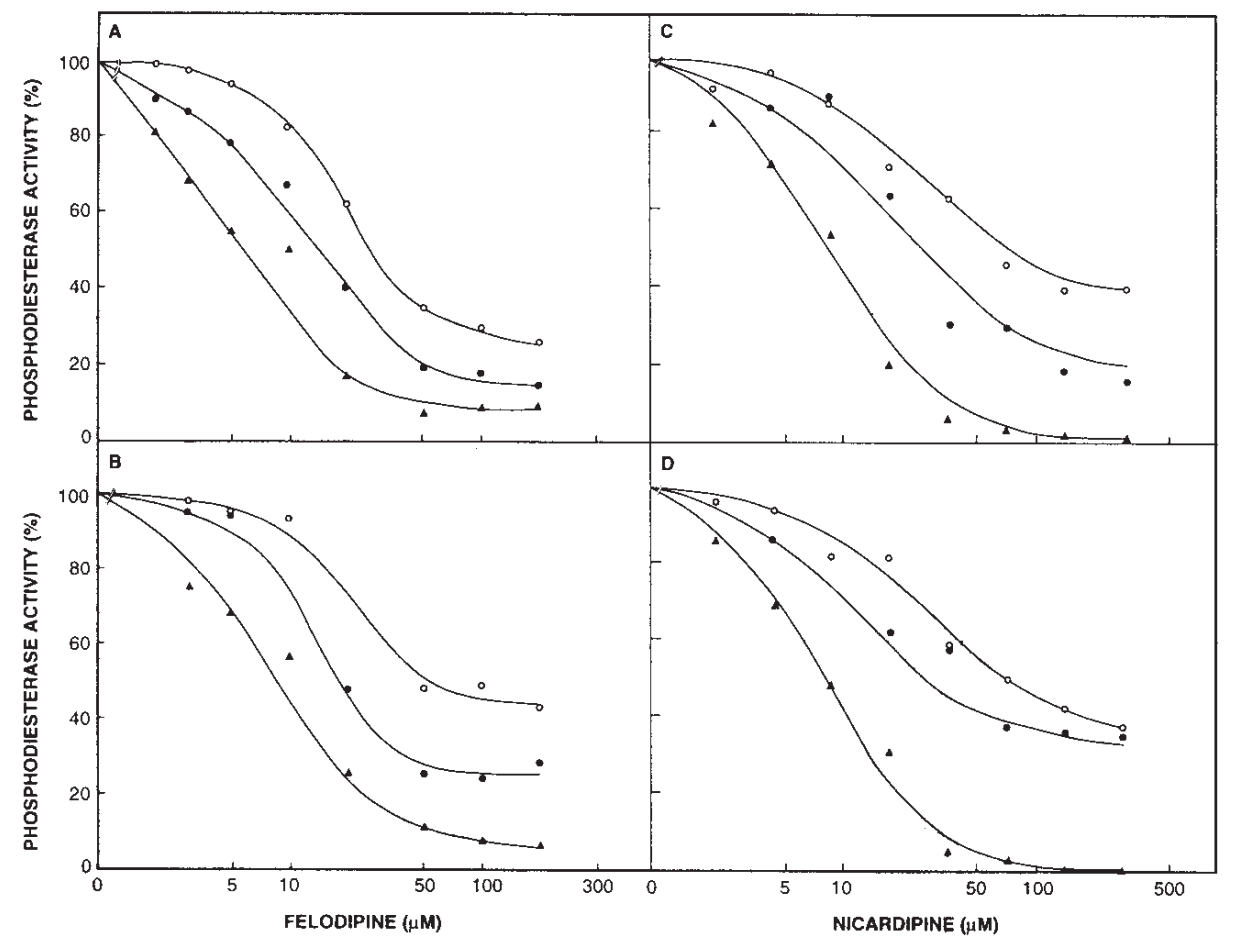

Figure 1. Effect of dihdropyridine $\mathrm{Ca}^{2+}$ antagonists on bovine brain PDE1 isozymes in the presence of $\mathrm{Ca}^{2+}$ and CaM. PDE1 activity was measured in the presence of three different concentrations of cAMP $(40 \mu \mathrm{M}, \mathbf{\Delta - \mathbf { \Delta }} ; 400 \mu \mathrm{M}, \bullet-\bullet ; 1.2 \mathrm{mM}$, o-o). PDE1A2 isozyme, A and C; PDE1B1 isozyme, B and D along with varied concentrations of felodipine (A and B) and nicardipine (C and D). For details of experimental conditions, see Sharma et al (38).

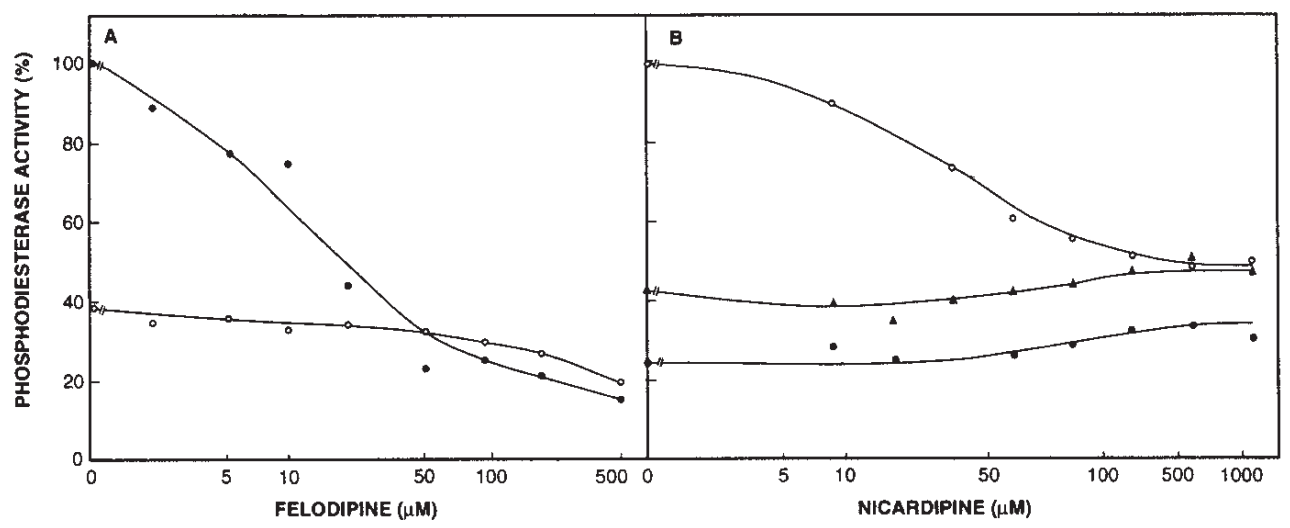

Figure 2. Specific binding site for dihydropyridine $\mathrm{Ca}^{2+}$ antagonists on bovine brain PDE1 isozymes. A, inhibition of PDE1A2 isozyme by various

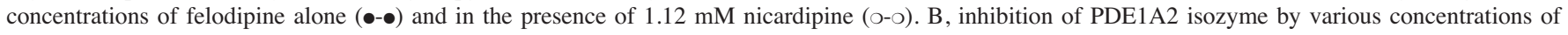
nicardipine alone (०-०) and in the presence of felodipine $(50 \mu \mathrm{M}, \mathbf{\Delta - \mathbf { \Delta }} ; 100 \mu \mathrm{M}, \bullet-\bullet)$. The enzyme activity was determined at $1.2 \mathrm{mM}$ cAMP in the presence of $\mathrm{Ca}^{2+}$ and CaM. For details of experimental conditions, see Sharma et al (38).

tissues, the capacity for hydrolysis of cyclic nucleotides by PDEs is $>10$ times the maximum rate of synthesis of cAMP and cGMP (13). Therefore, a partial inhibition of PDEs would result in many-fold increase in the level of cyclic nucleotides in the cell and thus the activation of cAMP-dependent protein kinase $(25,26)$. The PDE activity needs to be tightly regulated for proper functioning of the signaling pathways, which are linked to many cellular processes. Selective inhibitors are being discovered and used to regulate the PDE activities during normal pathological conditions.

A variety of pharmacological agents have been used to inhibit PDE1 isozymes, and this occurs mostly via $\mathrm{Ca}^{2+}$ dependent association with the proteins. Furthermore, in previous studies it was unclear which of the specific PDE1 isozymes were used. Moreover, these studies were carried out by using partially purified PDE1. We have demonstrated that PDE1 isozymes may be differentially inhibited by several pharmacological agents (Table IV).

Earlier studies have demonstrated that nicardipine does not have any significant differences in the inhibition of PDE1 isozymes (27); however, isobutylmethylxanthine (IBMX) exhibits marked differences in its inhibition potency for the PDE1A1, PDE1A2, and PDE1B1 isozymes (27). Ginsenosides are used for treatment of heart failure and to protect tissue from 
Table IV. Half maximal inhibition $\left(\mathrm{IC}_{50}\right)$ of various pharmacological agents on the activity of PDE1 isozymes.

\begin{tabular}{|c|c|c|c|c|c|c|c|}
\hline \multirow[b]{3}{*}{ Isozyme } & \multicolumn{7}{|c|}{ Pharmacological agents } \\
\hline & \multirow{2}{*}{$\begin{array}{c}\text { I BMX } \\
(\mu \mathrm{M})\end{array}$} & \multirow{2}{*}{$\begin{array}{l}\text { Nicardipine } \\
(\mu \mathrm{M})\end{array}$} & \multicolumn{3}{|c|}{ Ginsenoides } & \multirow{2}{*}{$\begin{array}{l}\text { Deprenyl } \\
(\mu \mathrm{M})\end{array}$} & \multirow{2}{*}{$\begin{array}{l}\text { Amantadine } \\
(\mu \mathrm{M})\end{array}$} \\
\hline & & & $\operatorname{Rc}(\mu \mathrm{M})$ & $\mathrm{Rb}(\mu \mathrm{M})$ & $\operatorname{Re}(\mu \mathrm{M})$ & & \\
\hline Heart PDE1A1 & 6.0 & 4.0 & 3.7 & 6.8 & 14.8 & $\mathrm{NC}$ & ND \\
\hline Brain PDE1A2 & 7.0 & 1.4 & 3.7 & 6.3 & 12.7 & 1.0 & 4.8 \\
\hline Brain PDE1B1 & 36.0 & 2.0 & ND & ND & ND & 2.0 & ND \\
\hline
\end{tabular}

NC, not carried out; ND, not detected. For details, see refs. 27,30-32.

damage when an organism is under stress $(28,29)$. Therefore, the effects of various ginsenosides were examined on bovine brain and heart PDE1 isozymes (30). We have demonstrated that ginsenosides were found to be potent inhibitors of PDE1A1 and PDE1A2 isozyme but not of PDE1B1 isozyme (30). Deprenyl (selegeline hydrochloride), which is a selective inhibitor of monoamine oxidase-B, inhibits PDE1A2 isozyme but is a poor inhibitor for PDE1B1 isozyme (31). In addition, amantadine is used for the treatment of Parkinson's disease and is also a potent drug for other disorders such as stroke, epilepsy, and neuroleptic malignant syndrome. It is interesting to note that amantadine only inhibits PDE1A2 isozymes but not the PDE1B1 and PDE1A1 isozymes (32). Since the inhibition of PDE1 isozymes by these compounds was overcome by increasing the concentration of $\mathrm{CaM}$, this suggests that these compounds act specifically and reversibly against the action of the CaM (30-32). Therefore, these compounds should be valuable tools to investigate the diverse physiological roles of distinct PDE1.

Some dihydropyridine $\mathrm{Ca}^{2+}$ antagonists show $\mathrm{CaM}$ antagonist activity and inhibit multiple PDE1 isozymes (33-37). However, it was not clear which of the PDE1 isozymes were used (33-37). Therefore, the effects of dihydrophyridine $\mathrm{Ca}^{2+}$ antagonists were examined on PDE1A2 and PDE1B1 isozymes at various concentrations of felodipine and nicardipines (38). The dose-dependence curve in the presence of $\mathrm{Ca}^{2+}$ and $\mathrm{CaM}$ at various concentrations of cAMP shows the effects of felodipine (Fig. 1A and B) and nicardipine (Fig. 1C and D) on the PDE1A2 and PDE1B1 isozymes, respectively. These results suggest that felodipine and nicardipine appear to be only partially competitive inhibitors because inhibition of PDE1 isozymes by felodipine and nicardipine does not approach $100 \%$ at high concentration of substrate (cAMP). In addition, this suggests that dihydropyridine $\mathrm{Ca}^{2+}$-antagonist binds to an enzyme site distinct from the active site. To further substantiate that PDE1 isozymes contain specific dihydropyridine $\mathrm{Ca}^{2+}$-antagonist binding sites distinct from the enzyme-active site, the inhibition of PDE1A2 isozyme was carried out by various concentrations of felodipine and in the presence of nicardipine (Fig. 2A) or by various concentrations of nicardipine and in the presence of felodipine (Fig. 2B). The results suggest that both nicardipine and felodipine bind at a specific site and, therefore, counteract each other's effect on the enzyme activity. This study is the first to substantiate the existence of specific sites, distinct from the active site on PDE1, that show high-affinity binding of these drugs. Felodipine and nicardipine have similar affinities for the PDE1A2 isozyme but bring about different levels of enzyme inhibition. This suggests the possibility of designing specific drugs that protect the enzyme from inhibition by such $\mathrm{Ca}^{2+}$ antagonists. As such, the possible molecular mechanisms of the interaction between drugs and intracellular targets require further study.

\section{Role of proteolysis in regulating PDE1A2}

Sequences containing several regions rich in proline $(\mathrm{P})$, glutamic acid $(\mathrm{E})$, serine $(\mathrm{S})$ and threonine $(\mathrm{T})$ are known as 'PEST' regions. The PEST regions have been suggested to be recognized by specific proteases, particularly the $\mathrm{Ca}^{2+}$ dependent cysteine proteases, calpains $(39,40)$. Calpains are one of the major mediators for the $\mathrm{Ca}^{2+}$ signal in many biological systems and they are ubiquitously expressed in all tissues $(41,42)$.

We have shown that PDE1 is proteolyzed by $m$-calpain (43). Proteolytic cleavage of PDE1A2 by $m$-calpain generated a $45 \mathrm{kDa}$ immunoreactive fragment, which is an active CaM-independent form (Fig. 3, inset). The time course of conversion of PDE1A2 into a CaM-independent form is shown in Fig. 3. The presence of $\mathrm{CaM}$ in the proteolytic reaction did not have any effect on PDE1A2 activity, suggesting that the interaction between $\mathrm{CaM}$ and PDE1A2 does not alter substrate recognition by calpain (Table V). High molecular weight CaM-binding protein (HMWCaMBP), which was discovered in our laboratory (44), is homologous to capastatin (45) an endogenous inhibitor of calpains and did not alter PDE1A2 activity but did inhibit calpain-mediated proteolysis (Table V). A CaM overlay using biotinylated CaM revealed that the $45 \mathrm{kDa}$ fragment does not contain the $\mathrm{CaM}$ binding domain (43). Furthermore, the phosphorylation of PDE1A2 by cAMP-dependent protein kinase and treatment with $m$-calpain resulted in generation of the $45 \mathrm{kDa}$ fragment, suggesting that phosphorylation does not protect PDE1A2 from $m$-calpain action. A previous study on connexin-32 indicated that its phosphorylation by protein kinase $\mathrm{C}$ prevents proteo- 
Table V. Effect of $m$-calpain on PDE1A2 activity.

\begin{tabular}{lrr}
\hline & \multicolumn{2}{c}{ PDE1A2 activity $^{\mathrm{a}}$} \\
\cline { 2 - 3 } & $\mathrm{Ca}^{2+} / \mathrm{CaM}$ & \multicolumn{1}{c}{ EGTA } \\
\hline PDE1A2 & $42.7 \pm 1.0$ & $4.2 \pm 0.2$ \\
-calpain & $1.0 \pm 0.0$ & $1.0 \pm 0.0$ \\
PDE1A2 + EGTA + $m$-calpain & $45.0 \pm 1.9$ & $3.8 \pm 0.2$ \\
PDE1A2 + $\mathrm{Ca}^{2+}+m$-calpain & $48.8 \pm 1.1$ & $47.5 \pm 1.0$ \\
PDE1A2 + $\mathrm{Ca}^{2+}+\mathrm{CaM}+m$-calpain & $46.6 \pm 1.0$ & $44.2 \pm 1.4$ \\
PDE1A2 + calpastatin & $42.1 \pm 1.6$ & $5.2 \pm 0.6$ \\
PDE1A2 + $\mathrm{Ca}^{2+}+$ calpastatin $+m$-calpain & $41.0 \pm 1.0$ & $4.1 \pm 0.3$ \\
\hline
\end{tabular}

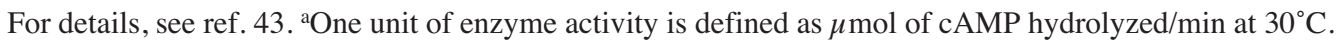

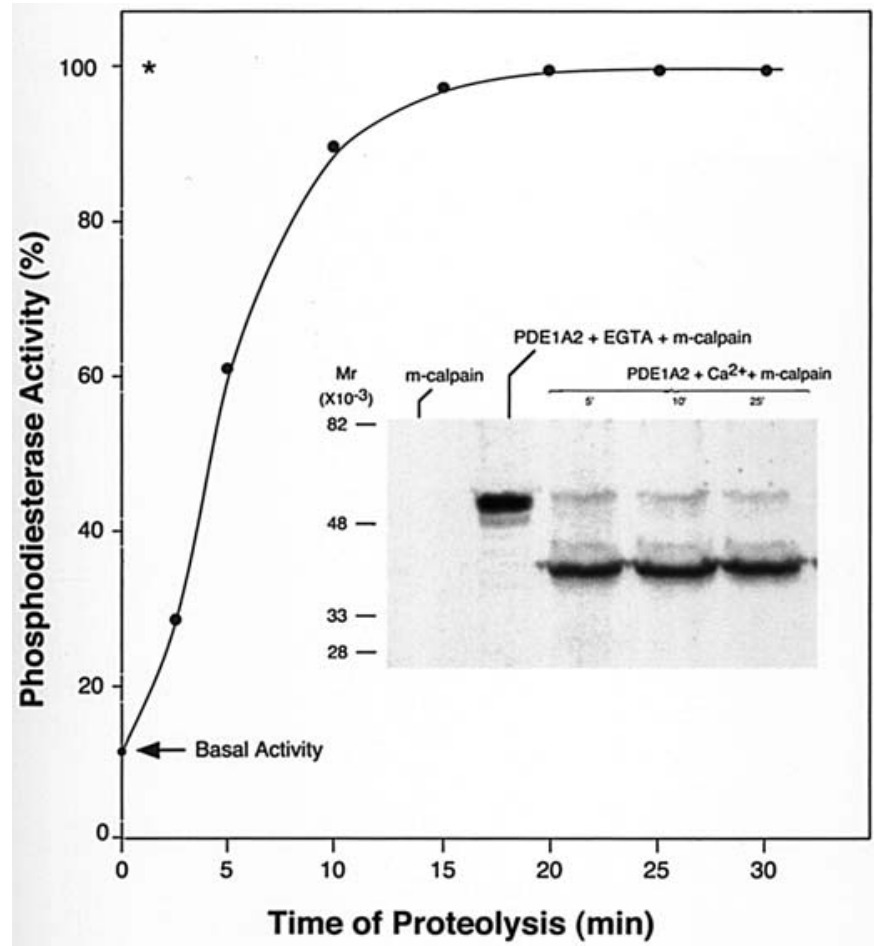

Figure 3. Effect of proteolysis on PDE1A2 activity. PDE1A2 was incubated with $m$-calpain in the presence of $\mathrm{Ca}^{2+}$, and at the times indicated proteolytic reaction was stopped with leupeptin and aliquots were assayed for activity in the presence of 5 mM EGTA. The arrow indicates the basal enzyme activity, in the presence of EGTA and absence of $m$-calpain; * indicates the activity of fully activated PDE1A2 in the presence of $\mathrm{Ca}^{2+} / \mathrm{CaM}$ and absence of $m$-calpain after $30 \mathrm{~min}$; the activity was taken as $100 \%$. Inset: Western blot analysis of PDE1A2 after incubation with $m$-calpain in the absence or presence of $\mathrm{Ca}^{2+}(43)$.

lysis by calpains (46). It has been shown that two serine residues of PDE1A2 are phosphorylated by cAMP-dependent protein kinase, at serine 112 and serine 120 (47). Our results suggested that the calpain cleavage site could be distant from the phosphorylation site (43). The cleavage site for calpains rarely resides in the PEST motif (48), although in some calpain substrates, PEST sequences are located near the cleavage site. PDE1A2 has a single PEST motif (residues 73-94), and calpain cleaves PDE1A2 after residue 126, which is 32 residues away from the PEST motif (43).

The domain organization of the PDE1A2 revealed that the native protein is a 530-residue polypeptide, a homodimer that is $\mathrm{N}^{\alpha}$-acetylated, and is composed of separate catalytic and regulatory domains $(49,50)$. From the $\mathrm{N}$-terminus, the CaM binding site is located from residue 23 to 41, the PEST motif from residue 73 to 94 and the phosphorylation site from residue 110 to 120 , respectively. The catalytic domain encompasses an approximately 250-residue sequence (139446) which is conserved among PDE1 isozymes of diverse size, phylogeny and function (6). Our analysis revealed that the molecular weight of this domain was $45 \mathrm{kDa}$, suggesting that the fragment is comprised of residues 139-530, when the enzyme is converted into a CaM-independent form. In view of the other domains, the most probable site for calpain cleavage could be between residues 120 and 138. This was confirmed by the N-terminal sequence analysis of the $45 \mathrm{kDa}$ fragment, which indicated that the calpain cleavage occurs between residues Glutamine 126 and Alanine 127 (Fig. 4).

The findings suggest that the proteolysis of PDE1A2 by $m$-calpain results in a $\mathrm{CaM}$-independent form which in turn could decrease the intracellular levels of cAMP (43). The potential role of PDE1 isozymes in the pathogenesis of certain neurological conditions remains an important area of investigation. However, there is considerable evidence that cAMP is involved in various neuronal functions, including synaptic transmission and neuron survival (51-54). It has been reported that in patients having Parkinson's disease with dementia, there is a significant decrease in cAMP (55). Earlier, we have demonstrated that PDE1A2 is inhibited by antiparkinsonian agents, suggesting a potential role of PDE1 in Parkinson's disease $(31,32)$. Since PDE1A2 is predominantly expressed in brain $(6,53,56)$, its colocalization with calpains in the same regions which contain $\mathrm{D}_{1}$ and $\mathrm{D}_{2}$ receptors can affect the cAMP signal. In certain pathophysiological conditions, an increase in $\mathrm{Ca}^{2+}$ influx as a result of inositol trisphosphate generation or via stimulation of glutamate receptors would attenuate the duration and magnitude of the cAMP signal. This could occur either by activating PDE1 and/or by activating calpain, which in turn can cleave PDE1, making it independent of CaM. Since PDE1A2 also has an 


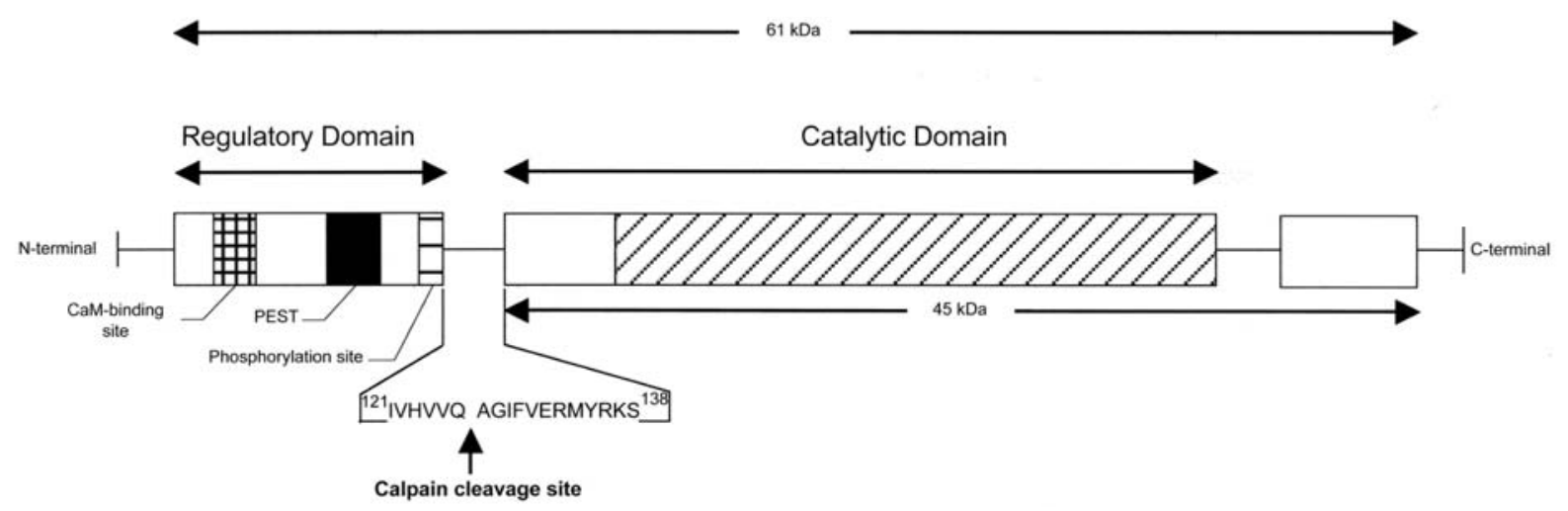

Figure 4. A representation of the PDE1A2 showing the cleavage site by $m$-calpain. The regulatory and catalytic domains are shown. The lined, black, and checkered boxes represent the CaM-binding domain, PEST, and phosphorylation site followed by conserved catalytic domain (hatched area), respectively (43). The arrow indicates the $m$-calpain cleavage site between residues Glutamine $126(\mathrm{Q})$ and Alanine $127(\mathrm{~A})$.

A

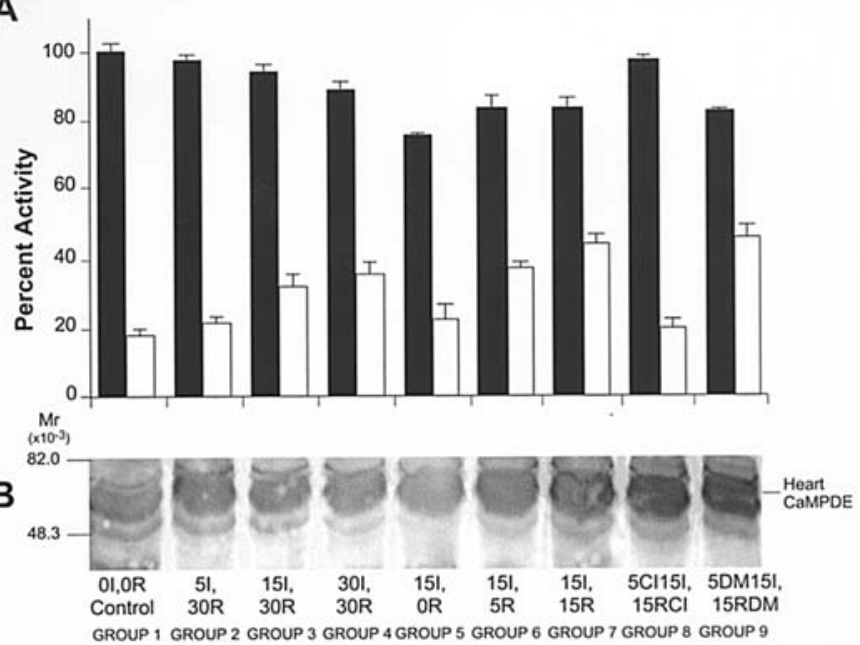

Experimental Groups

Figure 5. PDE1A1 activity in experimental groups of rat heart ischemiareperfusion. A, PDE1A1 activity in the presence of $\mathrm{Ca}^{2+} / \mathrm{CaM}$ (closed bar) or EGTA (open bar). B, Immunoblot of PDE1A1 from normal and ischemia-reperfusion rat heart tissues supernatant. Group 1, control (no ischemia or perfusion); group 2, $5 \mathrm{~min}$ ischemia, $30 \mathrm{~min}$ reperfusion (5I, 30R); group 3, $15 \mathrm{~min}$ ischemia, $30 \mathrm{~min}$ reperfusion (15I, 30R); group 4, $30 \mathrm{~min}$ ischemia, $30 \mathrm{~min}$ reperfusion (30I, 30R); group 5, $15 \mathrm{~min}$ ischemia, $0 \mathrm{~min}$ reperfusion (15I, 0R); group 6, $15 \mathrm{~min}$ ischemia, $5 \mathrm{~min}$ reperfusion (15I, 5R); group 7, $15 \mathrm{~min}$ ischemia, $15 \mathrm{~min}$ reperfusion (15I, 15R); group 8 , hearts were perfused with $100 \mu \mathrm{M}$ calpain inhibitor in $0.1 \%$ DMSO for $5 \mathrm{~min}$ before $15 \mathrm{~min}$ of ischemia and again during $15 \mathrm{~min}$ reperfusion (5CI15I, 15RCI) (CI, calpain inhibitor (ALLM); and group 9, with $0.1 \%$ DMSO alone as described in group 8 (5DM15I, 15RDM) (DM, dimethyl sulfoxide). Values are mean \pm SD of two samples in each group (57).

affinity for cGMP (14), calpains can also affect the cGMP signal. The activation of PDE1 by calpains could be an alternative physiological mechanism to regulate cAMP concentration in the cells by activating enzymes which are otherwise regulated reversibly by $\mathrm{Ca}^{2+} / \mathrm{CaM}$. It may be particularly important in neurons which undergo cyclical changes in intracellular $\mathrm{Ca}^{2+}$ during neurotransmission as well as for neuronal gene expression. The regulation of PDE1 by $m$-calpain may provide an important route for controlling the intracellular level of cAMP and the physiological processes regulated by these messenger molecules.

\section{Role of PDE1A1 in ischemic-reperfused heart}

The role of PDE1A1 in cardiac ischemia remains unknown. Therefore, we examined PDE1A1 activity and expression, cAMP concentration and the effect of a calpain inhibitor in cardiac ischemic-reperfused rat model (57). We demonstrated, for the first time, that ischemia-reperfusion injury to rat myocardium alters the activity of heart PDE1A1 while having minimal effects on cAMP concentrations (57). The total PDE1A1 activity (Fig. 5A ) and expression (Fig. 5B) in rat heart was largely unchanged under various conditions of ischemia and reperfusion. However, the basal activity which is independent of $\mathrm{Ca}^{2+} / \mathrm{CaM}$, increased with increasing degree of ischemia reperfusion (Fig. 5A). Pretreatment of rat hearts with cell permeable calpain inhibitor (ALLM, N-Ac-Leu-Leumethioninal) appeared to have a protective effect on PDE1A1 activity as total PDE1A1 activity in this group was found to be $97 \%$ of the control group (Fig. 5A). However, protein expression of PDE1A1 was not altered in the ischemic and reperfused rat hearts as indicated (Fig. 5B).

The protective effect of calpain inhibitor upon PDE1A1 in rat heart appears to be due to a decrease in calpain-mediated proteolysis of PDE1A1. In vitro incubation of PDE1A1 with $\mu$ - and $m$-calpain demonstrated that the PDE1A1 isozyme was susceptible to proteolysis by the calpains (Fig. 6). Furthermore, we have reported that $m$-calpain was capable of generating CaM-independent forms of PDE1A2 proteolysis (43). This study reports the first observed proteolysis of heart PDE1A1 by both $\mu$ - and $m$-calpain (57). Such a pathway allows for decoupling of the $\mathrm{Ca}^{2+}$ signal from PDE1A1 under sustained conditions of increased intracellular $\mathrm{Ca}^{2+}$.

While PDE1A1 activity varied in our experimental model (Fig. 5A), the total cAMP concentrations in rat myocardium appeared to be only slightly affected (Fig. 7). The generation of a CaM-independent PDE1 during ischemic events may therefore allow for the maintenance of cAMP levels in the face of $\mathrm{Ca}^{2+}$ derangements, which follow ischemic events (58). During reperfusion, an increased uptake of $\mathrm{Ca}^{2+}$ has been observed in myocytes (59), which would be capable of activating calpains. These activated calpains could then proteolyse PDE1A1 and irreversibly activate it, preventing the potentially toxic accumulation of cAMP in myocytes. 


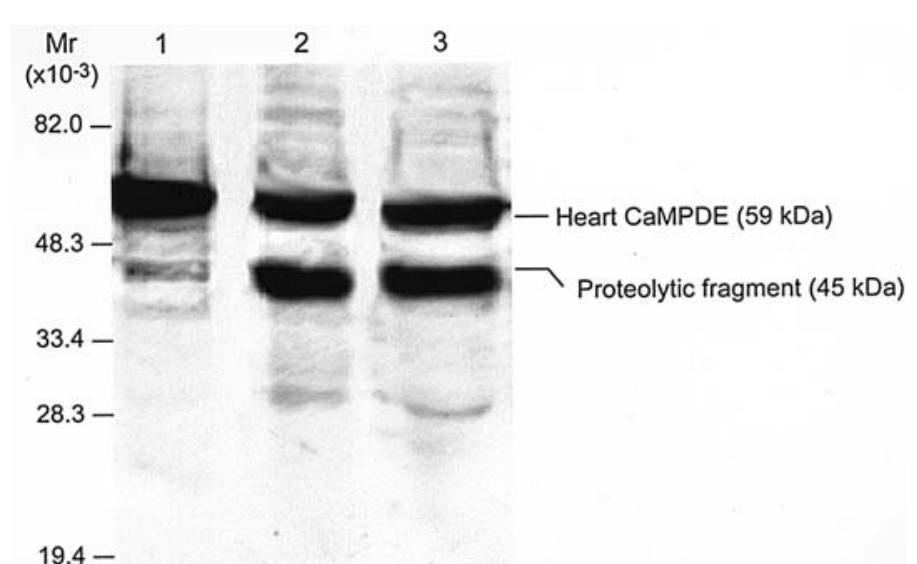

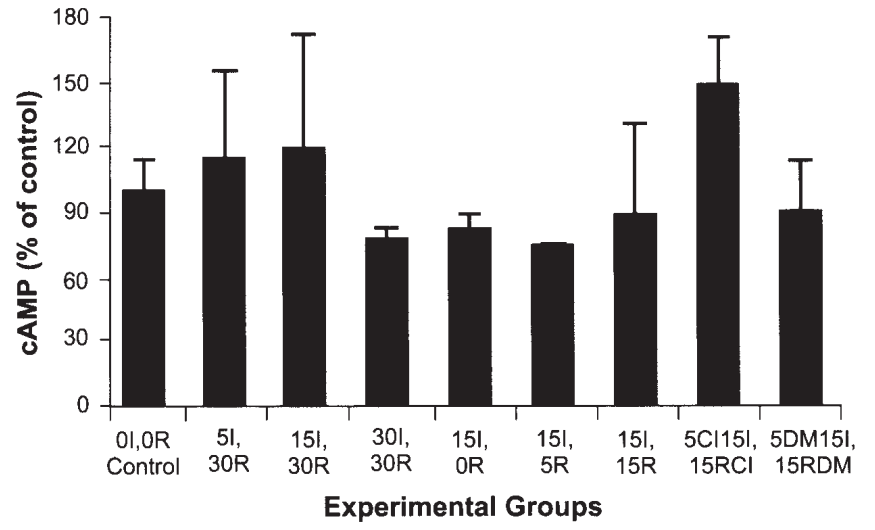

Figure 7. cAMP concentrations in experimental groups of ischemiareperfusion in heart. Details for various groups, see Fig. 5. Values are mean \pm SD of two samples in each group (57).

stability of thin and thick filaments, respectively $(76,77)$. Other cardiac contractile proteins including desmin, troponin ( $\mathrm{T}, \mathrm{C}$ and I), filaments, nebulin, gelsolin, titin, $\alpha$-actinin, and myosin also act as substrates of calpains (77-82). Their degradation can result in the contractile derangements and disassembly of sarcomere proteins caused by myocardial ischemia and could also be important for other pathological conditions $(77,82)$. Therefore, calpains have a unique specificity for degradation of those structural proteins that serve to keep actin and myosin assembled in the form of myofibrils. Calpains are also widely distributed in myocytes and are implicated in myocardial stunning and ischemia reperfusion injury $(61,62,66)$. Increased disruption of microtubules is associated with its action, by increasing intracellular $\mathrm{Ca}^{2+}(63)$.

While cAMP is necessary for the normal and effective cardiac function $(83,84)$, it has also been shown to have arrythmogenic effects, which can be demonstrated by the use of PDE inhibitors (28). A loss of cardiac response to $B$-adrenergic receptor stimulation, which increases cAMP, has also been documented in cardiac tissue under ischemic and cardiac failure conditions $(85,86)$. By preserving the degradative portion of the cAMP pathway via generation of CaM-independent PDE, a physiologic mechanism of maintaining cAMP in acute and chronic myocardial injury exists, thereby preventing further myocardial damage. Thus, a dynamic interaction between calpains and PDE1A1 in an ischemia-reperfusion model of the heart may allow for the maintenance of physiological concentrations of cAMP during periods of hypoxic injury to the heart. This definitely merits further in-depth studies.

\section{Conclusion}

PDEs are the enzymes which terminate the action of cAMP and cGMP by hydrolyzing them to their respective 5'-nucleotide monophosphates. One of the most intensively studied PDEs is the PDE1 which is involved in the complex interactions between the cAMP and $\mathrm{Ca}^{2+}$ second messenger systems. Immunological, kinetic, activation and regulatory characterizations have revealed subtle differences between PDE1 isozymes. In addition, our in vitro studies suggest that degrade tropomyosin and $\mathrm{C}$ protein, which contribute to the 
the activity of PDE1 is selectively regulated by cross-talk between $\mathrm{Ca}^{2+}$ and cAMP signaling pathway. The different PDE1 isozymes can be distinguished by various pharmacological agents. This study leads to the possibility of developing PDE1 isozyme-specific inhibitors which may be therapeutically useful. Furthermore, we have shown that PDE1 is proteolyzed by a $\mathrm{Ca}^{2+}$-dependent cysteine protease, calpains. This study suggests that limited proteolysis by calpains could be an alternative mechanism for activation of PDE1. In addition, we have demonstrated PDE1A1 activity expression and effect of calpains in the rat model in vitro of cardiac ischemiareperfusion. The physiological functions of PDE1 isozymes are still not clear since most studies undertaken so far have been on in vitro systems; therefore, it is essential that further research be directed to in vivo studies.

\section{Acknowledgements}

This work was supported by the Heart and Stroke Foundation of Saskatchewan, Canada. We are thankful to Mrs. Carla Deschamps and Miss Melissa Mick for typing the report and Mr. Todd Reichert for the photographic work.

\section{References}

1. Appleman MM, Ariano MA, Takemoto DJ and Whitson RH: Handbook of Experimentsl Pharmacology. Nathansons JA and Kebabian JW (eds). Springer-Verlag Berlin, New York, pp261-299, 1982.

2. Beavo JA, Hansen RS, Harrison SA, Hurwitz RL, Matins TJ, and Mumby MC: Identification and properties of cyclic nucleotide phosphodiesterases. Mol Cell Endocrinol 28: 387-410, 1982.

3. Sharma RK: Diversity of calcium action in regulation of calmodulin-dependent cyclic nucleotide phosphodiesterase. Indian J Biochem Biophys 40: 77-91, 2003.

4. Kakkar R, Raju RVS and Sharma RK: Calmodulin-dependent cyclic nucleotide phosphodiesterase. Cell Mol Life Sci 55: 1164-1185, 1999

5. Sharma RK and Hickie RA: $\mathrm{Ca}^{2+} /$ Calmodulin-dependent cyclic nucleotide phosphodiesterase. In: Phosphodiesterase Inhibitors. Dent G, Rabe K and Schudt C (eds). Academic press, New York, pp65-79, 1996.

6. Beavo JA: Cyclic nucleotide phosphodiesterase: functional implications of multiple isoforms. Physiol Rev 75: 725-748, 1995.

7. Manganiello VC, Murata T, Taira M, Belfrage P and Degerman E: Diversity in cyclic nucleotide phosphodiesterase isoenzyme families. Arch Biochem Biophys 322: 1-13, 1995.

8. Wang JH, Sharma RK and Mooibrock MJ: Calmodulinstimulated cyclic nucleotide phosphodiesterase. Mol Pharm Cell Reg 2: 19-59, 1990.

9. Sharma RK, Mooibrock MJ and Wang JH: Calmodulinstimulated cyclic nucleotide phosphodiesterase isozymes. In: The Molecular Aspects of Cellular Regulation. Cohen P and Klee CB (eds). Elsevier, Amsterdam, pp265-295, 1988.

10. Wells JN and Hardman JG: Cyclic nucleotide phosphodiesterase. Cyclic Nucleotide Res 8: 119-143, 1977.

11. Sharma RK, Adachi AM, Adachi K and Wang JH: Demonstration of bovine brain calmodulin-dependent cyclic nucleotide phosphodiesterase isozymes by monoclonal antibodies. J Biol Chem 259: 9248-9254, 1984.

12. Beavo JA, Conti M and Heaslip RJ: Multiple cyclic nucleotide phosphodiesterases. Mol Pharmacol 46: 399-405, 1994.

13. Dousa TP: Cyclic-3', 5'-nucleotide phosphodiesterase isozymes in cell biology and pathophysiology of the kidney. Kidney Int 55: 29-62, 1999.

14. Sharma RK, Tan Y and Raju RVS: Calmodulin-dependent cyclic nucleotide phosphodiesterase from bovine eye: high calmodulin affinity isozyme immunologically related to the brain $60 \mathrm{kDa}$ isozyme. Arch Biochem Biophys 339: 40-46, 1997.
15. Sharma RK and Kalra J: Characterization of calmodulindependent cyclic nucleotide phosphodiesterase isozymes. Biochem J 299: 97-100, 1994.

16. Hansen RS and Beavo JA: Differential recognition of calmodulin-enzyme complexes by a conformation-specific anti-calmodulin monoclonal antibody. J Biol Chem 261: 14636-14645, 1986.

17. Mutus B, Karuppiah H, Sharma RK and MacManus JP: The differential stimulation of brain and heart cyclic-AMP phosphodiesterase by oncomodulin. Biochem Biophys Res Commun 131: 500-506, 1985.

18. Keravis TM, Duemler BH and Wells JM: Calmodulin sensitive phosphodiesterase of porcine cerebral cortex: kinetic behaviour, calmodulin activation and stability. J Cyclic Nucleotide Protein Phosphor Res 11: 365-372, 1986.

19. Sharma RK and Wang JH: Purification and characterization of bovine lung calmodulin-dependent cyclic nucleotide phosphodiesterase. An enzyme containing CaM as a subunit. J Biol Chem 261: 14160-14166, 1986.

20. Sharma RK: Phosphorylation and characterization of bovine heart calmodulin-dependent phosphodiesterase. Biochemistry 30: 5963-5968, 1991.

21. Sharma RK and Wang JH: Differential regulation of bovine brain calmodulin-dependent cyclic nucleotide phosphodiesterase isozyme by cyclic AMP-dependent protein kinase and calmodulin-dependent phosphatase. Proc Natl Acad Sci USA 82: 2603-2607, 1985.

22. Sharma RK, Seitz DP, Singh B and Tan Y: Localization and regulation of bovine eye calmodulin-dependent cyclic nucleotide Phosphodiesterase by cyclic AMP-dependent protein kinase. Int J Mol Med 10: 17-23, 1996.

23. Sharma RK and Wang JH: Calmodulin and $\mathrm{Ca}^{2+}$ dependent phosphorylation and dephosphorylation of 63-kDa subunitcontaining bovine brain calmodulin-stimulated cyclic nucleotide phosphodiesterase isozyme. J Biol Chem 261: 1322-1328, 1986.

24. Zhang GY, Wang JH and Sharma RK: Bovine brain calmodulindependent protein kinase II: Molecular mechanism of autophosphorylation. Biochem Biophys Res Commun 191: 669-674, 1993.

25. Perry MJ and Higgs GA: Chemotherapeutic potential of phosphodiesterase inhibitors. Curr Opin Chem Biol 2: 472-481, 1998.

26. Rotella DP: Phosphodiesterase 5 inhibitors: Current status and potential applications. Nat Rev Drug Discov 1: 674-682, 2002.

27. Wu Z, Sharma RK and Wang JH: Catalytic and regulatory properties of CaM-stimulated phosphodiesterase isozymes. Adv Second Messenger Phosphoprotein Res 25: 29-43, 1992.

28. Chen X: Cardiovascular protection by ginsenosides and their nitric oxide releasing action. Clin Exp Pharmacol Physiol 23: 728-732, 1996.

29. Takahashi M and Tokuyama S: Pharmacological and physiological effects of ginseng on actions induced by opiods and psycho stimulants. Methods Find Exp Clin Pharmacol 20: 77-84, 1998.

30. Sharma RK and Kalra J: Ginsenoides are potent and selective inhibitors of some calmodulin-dependent phosphodiesterase isozymes. Biochemistry 32: 4975-4978, 1993.

31. Kakkar R, Raju RVS, Rajput AH and Sharma RK: Inhibition of calmodulin-dependent cyclic nucleotide phosphodiesterase isozymes by deprenyl. Life Sci 59: 337-341, 1996.

32. Kakkar R, Raju RVS, Rajput AH and Sharma RK: Amantadine: An antiparkinsonian agent inhibits bovine brain $60 \mathrm{kDa}$ calmodulin-dependent cyclic nucleotide phosphodiesterase isozyme. Brain Res 749: 290-294, 1997.

33. Epstein PM, Fiss K, Hachisu R and Andrenyak M: Interaction of calcium antagonists with cyclic AMP phosphodiesterase and calmodulin. Biochem Biophys Res Commun 105: 1142-1149, 1982 .

34. Minocherhomjee AE and Roufogalis BD: Antagonism of calmodulin and phosphodiesterase by nifedipine and related calcium entry blockers. Cell Calcium 5: 57-63, 1984.

35. Ronca-Testoni S, Hrelia S, Hakim G and Rossi CA: Interaction of smooth muscle relaxant drugs with calmodulin and cyclic nucleotide phosphodiesterase. Experimentia 41: 75-76, 1985.

36. Bostrom SL, Westerlund C, Rochester S and Vogel HJ: Binding of a dihydropyridine felodipine-analogue to calmodulin and related calcium binding proteins. Biochem Pharmacol 37: 3723-3728, 1988. 
37. Walsh MP, Sutherland C and Scott-Woo GC: Effects of felodipine (a dihydropyridine calcium channel blockers) and analogues on calmodulin-dependent enzymes. Biochem Pharmacol 37: 1569-1580, 1988.

38. Sharma RK, Wang JH and Wu Z: The mechanisms of inhibition of calmodulin-stimulated cyclic nucleotide phosphodiesterase by dihydrophyridine calcium antagonist. J Neurochem 69 : 845-850, 1997 .

39. Rogers S, Wells R and Rechsteiner M: Amino acid sequences common to rapidly degraded proteins: the PEST hypothesis. Science 234: 364-368, 1986

40. Rechsteiner M and Rogers S: PEST sequences and regulation by proteolysis. Trends Biochem Sci 21: 267-271, 1996

41. Croall DE and De Martino GN: Calcium-activated neutral protease (calpain) system: structure, function and regulation. Physiol Rev 71: 813-447, 1991.

42. Sorimachi H, Ishiura S and Suzuki K: Structure and physiological function of calpains. Biochem J 328: 721-732, 1997.

43. Kakkar R, Raju RVS and Sharma RK: In vitro generation of an active calmodulin-independent phosphodiesterase (PDE1A2) by $m$-calpain. Arch Biochem Biophys 358: 320-328, 1998.

44. Sharma RK: Purification and characterization of novel calmodulin-binding protein from cardiac muscle. J Biol Chem 265: 1152-1157, 1990.

45. Kakkar R, Raju RVS, Mellgren RL, Radhi JM and Sharma RK: Cardiac high molecular weight calmodulin-binding protein contains calpastatin activity. Biochemistry 36: 11550-11555, 1997.

46. Elvira M, Diez JA, Wang KK and Villalobo A: Phosphorylation of connexin-32 by protein kinase $\mathrm{C}$ prevents its proteolysis by $\mu$ and $m$-calpain. J Biol Chem 268: 14294-14300, 1993.

47. Florio VA, Sonnenburg WK, Johnson R, Kwak KS, Jensen GS, Walsh KA and Beavo JA: Phosphorylation of the $61 \mathrm{kDa}$ calmodulin-stimulated cyclic nucleotide phosphodiesterase at serine 120 reduces its affinity for calmodulin. Biochemistry 33: 8948-8954, 1994

48. Carillo S, Pariat M, Steff AM, Jarielencontre I, Poulat F, Berta P and Piechaczyk M: PEST motifs are not required for rapid calpain mediated proteolysis of c-fos protein. Biochem J 313: 245-251, 1996.

49. Charbonneau H, Kumar S, Novack JP, Blumenthal DK, Griffin PR, Shabanowitz, J, Hunt DF, Beavo JA and Walsh KA: Evidence for domain organization within the $61 \mathrm{kDa}$ calmodulindependent cyclic nucleotide phosphodiesterase from bovine brain. Biochemistry 30: 7931-7940,1991.

50. Sonnenburg WK, Seger D and Beavo JA: Molecular cloning of a cDNA encoding the $61 \mathrm{kDa}$ calmodulin-stimulated cyclic nucleotide phosphodiesterase. Tissue-specific expression of structurally related isozymes. J Biol Chem 268: 645-652, 1993.

51. Houslay MD and Milligan G: Tailoring cAMP signaling responses through isoform multiplicity. Trends Biochem Sci 22: 217-224, 1997.

52. Montminy MR, Gonzalez GA and Yamamoto KK: Regulation of cAMP-inducible genes by CREB. Trends Neurosci 13: 184-188, 1990.

53. Kincaid RL, Balaban CD and Billingsley ML: Regional and developmental expression of calmodulin dependent cyclic nucleotide phosphodiesterase in rat brain. Adv Second Messenger Phosphoprotein Res 25: 111-122, 1992.

54. Cooper DMF, Mons N and Karpen JW: Adenylyl cyclases and the interaction between calcium and cAMP signaling. Nature 374: 421-424, 1995.

55. Nishino N, Kitamura N, Hashimoto T and Tanaka C: Transmembrane signaling systems in the brain of patients with Parkinson's disease. Rev Neurosci 4: 213-222, 1993.

56. Lal S, Sharma RK, McGregor C and Macaulay RJ: Immunohistological localization of calmodulin-dependent cyclic nucleotide phosphodiesterase in the human brain. Neurochem Res 24: 43-49, 1999.

57. Kakkar R, Seitz DP, Kanthan R, Rajala RVS, Radhi JM, Wang X, Pasha MK, Wang R and Sharma RK: Calmodulin-dependent cyclic nucleotide phosphodiesterase in an experimental rat model of cardiac ischemia-reperfusion. Can J Physiol Pharmacol 80: 59-66, 2002.

58. Sperelakis N: Regulation of calcium slow channels of heart by cyclic nucleotides and effects of ischemia. Adv Pharmacol 31: $1-24,1994$.

59. Fiolet JW and Baartscheer A: Cellular calcium homeostasis during ischemia: a thermodynamic approach. Cardiovas Res 45: 100-106, 2000.
60. Kakkar R, Wang X, Radhi JM, Rajala RVS, Wang R and Sharma RK: Decreased expression of high-moecluar-weight calmodulin-binding protein and its correlation with apoptosis in ischemia-reperfused rat heart. Cell Calcium 29: 59-71, 2001.

61. Iizuka K, Kawaguchi H and Kitabatake A: Effects of thiol protease inhibitors on fodrin degradation during hypoxia in cultured myocytes. J Mol Cell Cardiol 25: 1101-1109, 1993.

62. Yoshida K, Sorimachi Y, Fujiwara M and Hironaka K: Calpain is implicated in rat myocardial injury after ischemia or reperfusion. Jpn Circ J 59: 40-48, 1995.

63. Steenbergen C, Murphy E, Watts JA and London RE: Correlation between cytosolic free calcium, contracture, ATP and irreversible ischemic injury in perfused rat heart. Circ Res 66: 135-146, 1990.

64. Berridge MJ, Bootman MD and Lipp P: Calcium a life and death signal. Nature 395: 645-648, 1998

65. Saido TC, Sorimachi S and Suzuki K: Calpain: New perspectives in molecular diversity and physiological-pathological involvement. FASEB J 8: 814-822, 1994.

66. Gao WD, Liu Y, Mellgren R and Marban E: Intrinsic myofilament alterations underlying the decreased contractibility of stunned myocardium. A consequence of $\mathrm{Ca}^{2+}$-dependent proteolysis? Circ Res 78: 455-465, 1996.

67. Billger M, Wallin M and Karlsson JO: Proteolysis of tubulin and microtubule-associated proteins 1 and 2 by calpain I and II. Difference in sensitivity of assembled and disassembled microtubules. Cell Calcium 9: 33-44, 1988.

68. Hirai S, Kawasaki H, Yaniv Y and Suzuki K: Degradation of transcription factors, c-Jun and c-Fos, by calpain. FEBS Lett 287: 57-61, 1991.

69. De Jongh KS, Colvin AA, Wang KK and Catterall WA: Differential proteolysis of the full-length form of the L-type calcium channel alpha 1 subunit by calpain. J Neurochem 63: 1558-1564, 1994

70. Liu ZQ, Kunimastsu M, Ynag JP, Sasaki M and Okamoto T: Proteolytic processing of nuclear factor kappa B by calpain in vitro. FEBS Lett 385: 109-113, 1996.

71. Raju RVS, Kakkar R, Datla RSS, Radhi J and Sharma RK: Myristoyl-CoA: protein N-myristoyltransferase from bovine cardiac muscle: molecular cloning, kinetic analysis, and in vitro proteolytic cleavage by $m$-calpain. Exp Cell Res 241: 23-35, 1998.

72. Villa PG, Henzel WJ, Sensenbrenner M, Henderson CE and Pettmann B: Calpain inhibitors, but not caspase inhibitors, prevent actin proteolysis and DNA fragmentation during apoptosis. J Cell Sci 111: 713-722, 1998.

73. Bird JW, Carter JH, Triemer RE, Brooks RM and Spanier AM: Proteinases in cardiac and skeletal muscle. Fed Proc 39: 20-25, 1980.

74. Goll DE, Kleese WC, Okitanin A, Kumamoto T, Cong J and Kapprell HP: Historical background and current status of the $\mathrm{Ca}^{2+}$ dependent protease system. In: Intracellular Calcium Dependent Proteolysis. Mellgren RL and Murachi T (eds). CRC Press, Boca Raton, Florida, pp3-24, 1990.

75. Dayton WR, Reville WJ, Goll DE and Stromer MH: A Ca ${ }^{2+}$ activated protease possibly involved in myofibrillar protein turnover. Partial characterization of the purified enzyme. Biochemistry 15: 2159-2167, 1976.

76. Toyo-Oka T and Maaki T: Calcium-activated neutral protease from bovine ventricular muscle: isolation and some of its properties. J Mol Cell Cardiol 11: 769-786, 1979.

77. Koohmaraie M: Ovine skeletal muscle multicatalytic proteinase complex (proteasome): purification, characterization, and comparison of its effect on myofibrils with $\mu$-calpains. J Anim Sci 70: 3697-3708, 1992.

78. Tan FC, Goll DE and Otsuka Y: Some properties of the millimolar $\mathrm{Ca} 2^{+}$-dependent proteinase from bovine cardiac muscle. J Mol Cell Cardiol 20: 983-997, 1988.

79. Whipple G and Koohmaraie M: Degradation of myofibrillar proteins by extractable lysosomal enzymes and $m$-calpain, and the effects of zinc chloride. J Anim Sci 69: 4449-4460, 1991.

80. Selliah N, Brooks WH and Roszman TL: Proteolytic cleavage of alpha-actinin by calpain in T cells stimulated with anti-CD3 monoclonal antibody. J Immunol 156: 3215-3221, 1996.

81. Sorimachi H, Kimura S, Kinbara K, Kazama J, Takahashi M, Yajima H, Ishiura S, Sasagawa N, Nonaka I, Sugita H, Maruyama K and Suzuki K: Structure and physiological functions of ubiquitous and tissue-specific calpain species. Musclespecific calpain, p94, interacts with connectin/titin. Adv Biophys 33: 101-122, 1996. 
82. Huang $\mathrm{J}$ and Forsberg NE: Role of calpain in skeletal muscle protein degradation. Proc Natl Acad Sci USA 95: 12100-12105, 1998.

83. Hove-Madsen L, Mery PF, Jurevicius J, Skeberdis AV and Fischmeister R: Regulation of myocardial calcium channels by cyclic AMP metabolism. Basic Res Cardiol 91: 1-8, 1996.

84. Xiao RP, Cheng H, Shou YY, Kuschel M and Lakatta EG: Recent advances in cardiac beta (2)-adrenergic signal transduction. Circ Res 85: 1092-1100, 1999.
85. Stuver TP, Cove CJ and Hood WB Jr: Mechanical abnormalities in the rat ischemic heart failure model which lie downstream to cAMP production. J Mol Cell Cardiol 26: 1221-1226, 1994.

86. Nasa Y, Toyoshima H, Ohaku H, Hashizume Y, Sanbe A and Takeo S: Impairment of cGMP- and cAMP-mediated vasorelaxations in rats with chronic heart failure. Am J Physiol 271: H2228-H2237, 1996. 